\title{
Digitization in the German Health Care System - An Analysis of the Status Quo Using the Example of the Dental Sector
}

\author{
C. Maier and T. Juschkat
}

\begin{abstract}
According to the Federal Ministry of Economics and Energy, the German healthcare industry is growing faster than the economy as a whole but is regularly far behind compared to the rate of digitalization. Nonetheless, the healthcare industry offers great potential for digital applications. The brief overview at hand uses the example of treatment and cost plans in the dental field to illustrate the state of digitalization in the German health care system. The primary goal is to examine whether it is possible to transfer the principle of electronic data medium exchange for hospital settlements and the associated electronic data processing to the transmission of treatment and cost plans in the dental field. Anselstetter's (1984) expertise is fundamentally used to evaluate the benefits of electronic data processing and to a treatment and cost plan under critical evaluation. In order to determine relevant benefit effects for health insurance funds and dentists, a transfer and processing form of the treatment and cost plan is used based on a generated model. Applying this model can assist health insurance funds to identify effects regarding time, personnel reduction, and more efficient use of existing personnel structures. It also provides health insurance companies and dentists with an overview of the possible benefits of electronic data transmission and processing. Nonetheless, one of the problems is that it is not possible to calculate the expected costs due to the lack of empirical examinations. Consequently, a detailed cost- benefit evaluation of an electronic transmission and processing of the treatment and cost plans is unfeasible.
\end{abstract}

\section{INTRODUCTION}

The concept of digitization is becoming increasingly common in all areas of business and private life. As a result, it is gaining more and more importance in discussions about efficiency across the economy - including health economics aspects.

"The health economy is one of the largest economic sectors in Germany. It generated around 12 percent of the GDP in 2016 (...). However, in surveys on the degree of digitization, the health economy regularly performs very poorly." [3]. This statement by the Federal Ministery of Economics and Energy (BMWi) highlights the importance of the health sector. At the same time, the BMWi addresses the long-standing problem that digitization in the health sector is a secondary problem.

Demographic change in connection with the medical-

Published on June 8, 2020.

C. Maier, University of Bayreuth, Germany.

(e-mail: christian.maier@uni-bayreuth.de)

T. Juschkat, University of Bayreuth, Germany.

(e-mail: Tizian.L.Juschkat@stmail.uni-bayreuth.de) technical progress results in an increase of the expenditures for the supply of patients [12]. In combination with the obligation to contract and the ban on discrimination imposed on health insurers in order to increase competition, they are constantly forced to optimize their processes in the best way possible [13]. As a result, health insurance companies are converging towards commercial businesses in terms of organization and processes [6].

In this paper, the dental care sector, representing the fourth largest expenditure share of the health insurance funds, is examined more closely with regard to possible process optimizations [8]. In detail, the exchange of treatment and cost plans (HKP) is considered. These are sent by the patient, partly via dentist, to the responsible health insurance for approval and then sent back to the insured person and the responsible dentist, respectively. Social consensus as well as discussions with dentists and employees of a health insurance company (AOK) indicate that a huge deficit in digital networking structures can be identified.

\section{THEORY}

As pointed out by the BMWi mentioned above, it cannot be said that electronic ap-plications are used throughout the German health care system [3]. Although there are already some electronic systems existing, most of them are isolated solutions and therefore cannot fully tap the potential of interoperable systems. Reasons for this are political and infrastructural barriers, especially the legal regulations, which are predominantly found in the fifth social security statute book (SGB V).

With regard to economic sectors that have already successfully implemented the possibilities of digitization, it is clear that the healthcare sector is facing similar challenges [9]. The driving force is an increasing cost pressure on some of the players that, above all, encourages health insurance companies to make cost savings in all areas.

As a result, various models for process optimization are also being discussed in the field of dental care.

Dental care accounts for 13.793 billion Euros of the statutory health insurance (GKV) total expenditure volume, representing about $6.6 \%$ of the GKV's total expenditures of 200 billion Euros [8]. Within the volume of dental expenditure, about 3.26 billion Euros are spent on dental prostheses. Thus, these $23.7 \%$ dental prostheses represent the second largest cost block after conservative and surgical treatments at $57.6 \%$ [8].

In the field of dentistry, especially when it comes to 
dental prostheses, the health insurance companies comply with their obligation to fulfil the entitlement to benefits by determining the subsidy for the assumption of the pending treatment costs on the basis of a submitted HKP.

In addition to determining the entitlement to benefits, the HKP has the task of in-forming the patient about the expected total costs and the contribution to be paid by the patient through subdividing the planned benefits and remuneration. A patient's own contribution may be incurred for dental prostheses, since - according to the German Dentists' Fees Schedule - these are services that are provided on request and therefore do not fall within the scope of the reimbursable services [4].

The process chain of the HKP slightly differs from health insurance to health insurance. However, they are very similar in their basic structure. The differences within a health insurance group are partly recognizable. An example is the process chain of the Allgemeine Ortskrankenkasse (AOK) NORDWEST and the AOK HESSEN.

At the AOK Hessen, the process chain is as follows:

1. Completion of the HKP in the appropriate practice management software or by hand, after completion of the diagnosis and clarification of the patient's alternative services.

2. Postal dispatch of the completed HKP to the responsible health insurance company.

3. Document reading of the HKP by means of scan and EDP-moderate reading of the data.

4. Automatic, mechanical fall system, and, if required, post-processing by a clerk.

5. Determination of the amount of fixed subsidies using the processing system on the basis of a rule system and preparation of notes on existing deviations.

6. Final decision by the responsible person.

7. Print out the written information and send it by post to the insured and/or the dentist

The process chain at AOK NORDWEST differs in that the HKP is transferred to the management system manually. The processing of the HKP application takes about one to two weeks on average until it is returned to the insured person. The duration depends, for example, on the complexity of the HKP and the utilization of the fund [5].

In this form of electronic data acquisition, the data is visualized and therefore can only be viewed. If the digitized data is to be evaluated or used for other purposes, it must be typed or transmitted manually. This results in media disruptions that should be avoided by the system and entail certain risks and costs [11].

One system that is already being used to exchange invoices between hospitals and health insurance companies in Germany is electronic data exchange (DTA).

With the help of the DTA, the accounts of hospital cases are electronically transmitted to the responsible health insurance fund with the help of a standardized data code and automatically processed there by an algorithm (dark processing) [2].

\section{Potentials}

Considering electronic data processing, process optimization can be analyzed with regard to its economic benefits. Possible benefit effects as a base of an electronic data processing a graphic of Anselstetter can be quoted, which describes that a better information transmission and processing leads to three large effects. On the one hand, there is less documentation effort, which has a positive effect on the process throughput time. In addition, communication becomes much more efficient, since documents are transmitted faster, and problems can be solved more quickly. On the other hand, the procurement of information and the willingness to provide information happens faster. These are linked to more efficient communication and enable better process transparency and the creation of more precise key figures [10]. This allows better planning and forecasting accuracy to be achieved. The three effects form the basis of more efficient and faster decisions and decision-making processes [1].

In order to apply these considerations to the area of electronic transmission and processing of the HKP, a number of conditions are defined below:

Firstly, in addition to the electronic processing of the HKP, the exchange between the dental practice and the respective health insurance must take place electronically. As a form of comparison, the exchange of settlements by DTA between hospitals and insurance companies must be mentioned [8]. Within the exchange and processing the data must be kept throughout in original electronic data form, in order to avoid possible media breaks and at the same time ensure processing independently of time and place. The term original electronic means that the data is generated electronically and is not converted into digitized data during the entire process cycle [11]. In order to transmit the HKP, the existing "data highway" is used with which the invoices are transmitted from the dentist via the KZV to the insurance companies [8]. This satisfies the requirements of data protection and the KZVs have the option of collecting the HKP and passing on the data packets to the health insurers overnight. Further-more, the bonus booklets of the insured persons must be kept purely electronically at the health insurance funds in order to take the bonus into account in the fixed subsidies.

Under these conditions, there are time savings of one to two working days, as there is no need for transmission by post. If the HKP information is available to the health insurance funds in original electronic form, the time required for manual recording or scanning in the processing system of the respective fund is eliminated. As a result of the reduced expenditure of time, there is potential for personnel savings or personnel resources can be used more optimally elsewhere.

Thus, less personnel can work more efficiently due to the higher qualification level.

Possible error rates due to manual recording are completely resolved, filling errors though are still possible, which means that the errors continue until the algorithm or the clerk notices them in the final decision. The correction of the incorrect content or data structure can, however, be carried out more quickly since the file can be sent back to the dentist immediately and subsequently corrected. Furthermore, the process steps become more transparent since a fixed process path is prescribed and cannot be deviated from. Accordingly, the reduced transmission time 
has a positive effect. Because of the original electronic data structure, it is also possible to process the uncomplicated HKP using dark processing. This eliminates the need for routine tasks and more complex tasks can be processed more frequently. Thus, the existing expertise can be used more effectively and productivity increases.

Furthermore, the processing time of the HKP is reduced and consequently a larger number of HKP can be processed in the same time. The possibility of personnel and time savings in combination with a more efficient and effective distribution of personnel resources, allows the cash registers to improve their efficiency and increase their profitability at the same time. In addition, the personnel savings potential could be a way of counteracting the shortage of skilled workers in the wake of demographic change, which is making itself noticeable in all sectors of the economy. This could be done by qualifying the personnel to be made redundant or, alternatively, by reinvesting the personnel costs saved in the acquisition of the corresponding specialists.

However, it should be critically noted that the majority of possible benefits are to be attributed purely to the funds. Only faster processing can have a positive influence on patient satisfaction since treatment can be carried out more quickly and thus al-so provide dentists with additional benefits.

\section{Results/CONCLUSION}

As a result, the German health care system currently has a low degree of digitization compared to other economic sectors. There are different approaches and support systems, which are used by hospitals, health insurances, medical practices, and other actors. However, these are isolated systems and partly no longer up-to-date programs. The reasons for this are the legal hurdles and the specific areas of application, which make it more difficult for new providers in particular to enter the healthcare market. Nevertheless, many applications are in the start-up phase to gain a foothold in the German healthcare market.

Looking at the dental field, one starting point is the electronic transmission of the HKP for dental prostheses. The aim is to generate benefits for dental practices and health insurers with the help of electronic transmission and processing, similar to the DTA between hospital and insurance company. The main benefits are expected to be time and personnel savings through electronic transmission and application of dark processing in the HKP.

It can be assumed that there will be a significant reduction in the number of errors as a result of the automatic processing of routine tasks. This is possible because the manual transfer of the HKP to the corresponding processing system of the health insurance company and transmission of the HKP by scanning with subsequent correction would no longer be necessary.

Accordingly, the health insurance providers would be given the opportunity to re-structure their personnel and thus allocate more personnel resources to the complex tasks or, alternatively, to reduce the overstaffing. In addition, such process structures would result in enormous time savings in the transfer of HKP to the health insurance, as the antiquated postal route would be eliminated.

With regard to the various saving options, it should not be forgotten that it is not possible to express the benefit effects in concrete figures due to the lack of empirical sources and the complexity of the processes. In addition, it is not possible to give a complete picture of the expected costs for health insurances and dentists. This prevents a meaningful comparison of costs and benefits and thus leaves it open whether the benefits can outweigh the costs incurred or not. It should also be noted that the majority of potential benefits would benefit health insurance companies. The dentists would purely be responsible for the faster assessment of the HKP, the less complicated elimination of filling errors, and the related faster treatment of the patient. In addition, an increase in patient satisfaction could be mentioned because of the faster treatment. Accordingly, care should be taken to ensure that the costs of implementing and continuing to use the system are allocated in proportion to the expected benefits of the actors involved. This should prevent dentists from being assigned too large a share of the costs and exceeding the possible benefits.

Finally, electronic transmissions of the HKP seems to make economic sense. Especially the health insurances can realize various relevant benefits. It may be possible to develop the resulting electronic interoperability of the players involved and thus generate a measurable and greater benefit for dentists. In order to reduce the effort involved in creating and implementing a new software application, the existing data exchange between dentist and health insurance company could be used for dental billing. Thus, the examination of the dentists could be taken over equivalent by the responsible health insurance dental association.

However, it is questionable whether an agreement will be reached between the actors and whether electronic transmission will be introduced. A reason for it is the dental sector, which with an expenditure volume of around 13.7 billion Euros, is much smaller than the inpatient sector, which accounts for around 70.5 billion Euros. Accordingly, the savings potential in the dental sector is estimated to be much lower and pursued with less commitment, as the available resources are preferably used for new savings opportunities in the inpatient sector.

In conclusion, the comparatively low cost pressure on the part of the health insurance in the dental sector, the lack of a valid cost/benefit analysis and the necessary need for a joint cooperation of all parties involved, leaves the introduction of electronic transmission of the HKP either open or it would be an extremely lengthy process.

\section{REFERENCES}

[1] R. Anselstetter, Betriebswirtschaftlicher Nutzeneffekt der Datenverarbeitung, Be-triebs- und Wirtschaftsinformatik, Springer, Berlin, 1984.

[2] AOK-Bundesverband, Bundesverband der Betriebskrankenkassen, IKK-Bundesverband, Bundesverband der landwirtschaftlichen Krankenkassen, Bundesknappschaft, See-Krankenkasse, Verband der Angestellten-Krankenkassen e.V., AEV - Arbeiter-ErsatzkassenVerband e.V., Deutsche Krankenhausgesellschaft, 1994. Vereinbarung gemäß $\S 301$ Abs. 3 SGB V über das Verfahren zur Abrechnung und Übermittlung der Daten nach $\S 301$ Abs. 1 SGB V.

[3] Bundesministerium für Wirtschaft und Energie, Werkstatt Digitalisierung in der Ge-sundheitswirtschaft, 2017. 
[4] Bundeszahnärztekammer Arbeitsgemeinschaft der Deutschen Zahnärztekammern e.V., Gebührenordnung für Zahnärzte, 2011.

[5] P. Fay, C. Wedemann, R. Elm, Persönliches Interview zum Thema Heil- und Kos-tenpläne, 2018.

[6] K. Jähn, Institut für Medizinmanagement und Gesundheitswissenschaften (Eds.), E-Health im Spannungsfeld zwischen Entwicklung und Anwendung: Ta-gungsband 2, Symposium der Arbeitsgruppe E-Health \& Health Communica-tion, Schriftenreihe e-Health and healthcare communication, Akad. Verl.Ges. Aka, Berlin, 2007.

[7] Kassenärztliche Bundesvereinigung, Bundesverband der Ortskrankenkassen, Knappschaft, Seekrankenkasse, Bundesverband der Betriebskrankenkas-sen, Bundesverband der Innungskrankenkassen, Bundesverband der landw. Krankenkassen, Bundesmantelvertrag - Zahnärzte, 2017.

[8] Kassenzahnärztliche Bundesvereinigung, Kassenzahnärztliche Bundesvereinigung Abt. Statistik, KZBV Jahrbuch 2017 Statistische Basisdaten zur vertrags-zahnärztlichen Versorgung, 2017.

[9] D. Matusiewicz, L. Kaiser, Digitales Betriebliches Gesundheitsmanagement: Theorie und Praxis, FOM-Edition. Springer Gabler, Wiesbaden, 2018.

[10] S. Meister, S. Becker, F. Leppert, L. Drop, Digital Health, Mobile Health und Co. - Wertschöpfung durch Digitalisierung und Datenverarbeitung, in: Digitale Transformation von Dienstleistungen im Gesundheitswesen I, Springer Gab-ler, Wiesbaden, pp. 185-212, 2017.

[11] S. Müller-Mielitz, Digitalisierung der Gesundheitswirtschaft, in: EHealth-Ökonomie, Springer Fachmedien Wiesbaden $\mathrm{GmbH}$, Wiesbaden, 2017.

[12] E. Nagel, K. Alber, Das Gesundheitswesen in Deutschland: Struktur, Leistungen, Weiterentwicklung, 5. vollständig überarbeitete und erweiterte Auflage, ed. Deutscher Ärzte-Verlag, Köln, 2013.

[13] P. Oberender, A. Fibelkorn-Bechert, Ein zukunftsfähiges deutsches Gesundheitswe-sen: ein Reformvorschlag unter besonderer Berücksichtigung der ambulanten Versorgung, Schriften des Instituts für Angewandte Gesundheitsökonomie ( $\mathrm{IaG})$. Verl. PCO, Bayreuth, 1997. 